\title{
Single-dose Dexamethasone Suppression in Normal Subjects and Hospital Patients
}

\author{
C. K. CONNOLLY, ${ }^{*}+$ M.A., M.B., M.R.C.P.; M. B. R. GORE, $\dagger$ PH.D. ; N. STANLEY,* M.A., M.B., M.R.C.P.
}

M. R. WILLS, $\dagger$ M.D., M.C.PATH.

Brit. med. J., 1968, 2, 665-667

Nichols, Nugent, and Tyler (1965) reported that while a small single dose of $0.5 \mathrm{mg}$. of dexamethasone given at 08.00 or 16.00 hours to normal healthy male subjects caused only temporary suppression of cortisol production, the same dose given at midnight produced virtually complete suppression for 24 hours. This observation was used as the basis of a rapid simple single-dose dexamethasone suppression test for the diagnosis of Cushing's syndrome (Nugent, Nichols, and Tyler, 1965 ; Pavlatos, Smilo, and Forsham, 1965) in which plasma cortisol (17OHCS) levels were measured at 08.00 hours after administration of $1 \mathrm{mg}$. of dexamethasone at 23.00-24.00 hours. More recently McHardy-Young, Harris, Lessof, and Lyne (1967) reported results of a similar test in which a $2-\mathrm{mg}$. dexamethasone dose was used.

We wished to use a single-dose test on patients with chronic congestive cardiac failure in whom we had found a disturbance of the circadian rhythm in plasma cortisol levels and a diminished response to dexamethasone (Connolly and Wills, 1967).

In a preliminary study we attempted to find a dose of dexamethasone which, given at midnight, consistently suppressed the plasma cortisol level at 09.00 hours below the lower limits of the normal range for this time of day, not only in healthy controls but also in hospital inpatients. This paper presents our findings.

\section{Subjects and Methods}

Forty-nine normal subjects were studied. All were members of either the medical or ward staff of this hospital. No modifications of their normal daily routine occurred during the period of study.

One hundred and eight patients were studied. They were in the medical and surgical wards, and had either recovered from the acute cause of their admission to hospital or were at least seven days postoperative after surgical procedures. None of the patients had any clinical evidence of an endocrine disorder. Patients with chronic heart failure and severe hepatic or renal failure were excluded from the study. The purpose of the investigation was explained to the patients and their permission for the test to be made was obtained. All the patients studied followed their normal ward routine. Forty-seven were studied again as outpatients.

Both control and test blood samples were collected between 09.00 and 10.00 hours. Dexamethasone was given at 23.00 hours the night before the test. In those subjects where more than one dose level response was studied, at least 48 hours was allowed to elapse between the tests.

Plasma 11-hydroxycorticoids (11-OHCS) were measured by a modification of the Mattingly (1962) method. This method measures fluorimetrically both cortisol and corticosterone. As the normal circulating amount of the latter is small, the plasma 11-OHCS concentration is taken to be essentially a measure of plasma cortisol, though James, Townsend, and Fraser (1967) have found that a variable proportion of the total fluorescence is due to substances other than cortisol.

\section{Results}

Effect of Size of Dose.-In the 49 normal subjects 84 tests were performed to assess the response to a single dose of dexamethasone over the range $0.5-2 \mathrm{mg}$. The 0.900 hours control plasma 11-OHCS values of these subjects were in the range 7-31 $\mu \mathrm{g} . / 100 \mathrm{ml}$., with no significant difference between males (mean 17.7, S.D. 4.4) and females (mean 17.9, S.D. 6.2)

- Department of Medicine.

+ Department of Chemical Pathology.

Royal Free Hospital, N.W. Branch, London N.W.3.

$\ddagger$ Present address : Royal National Orthopaedic Hospital, London W.1.

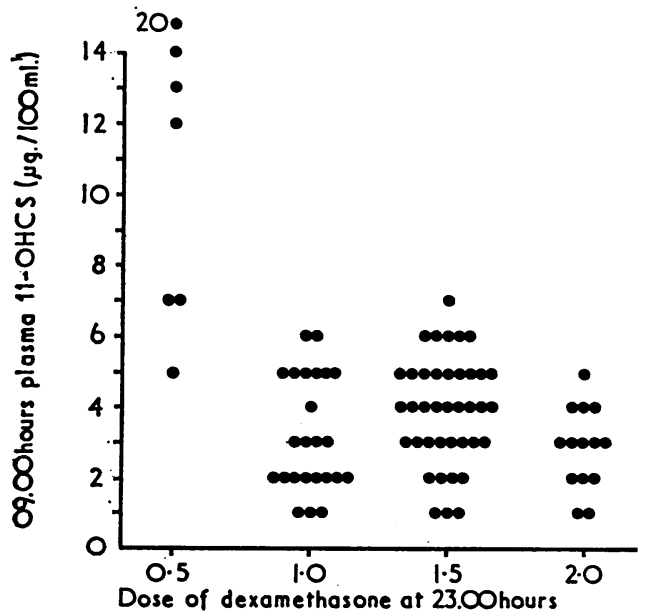

Fic. 1

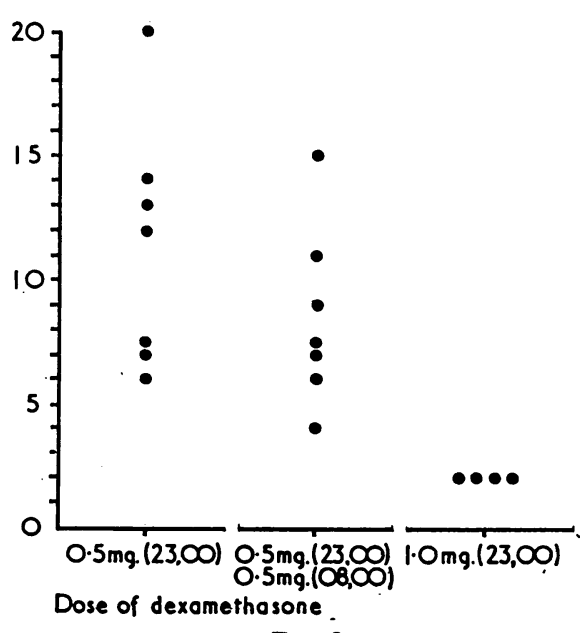

Fig. 2

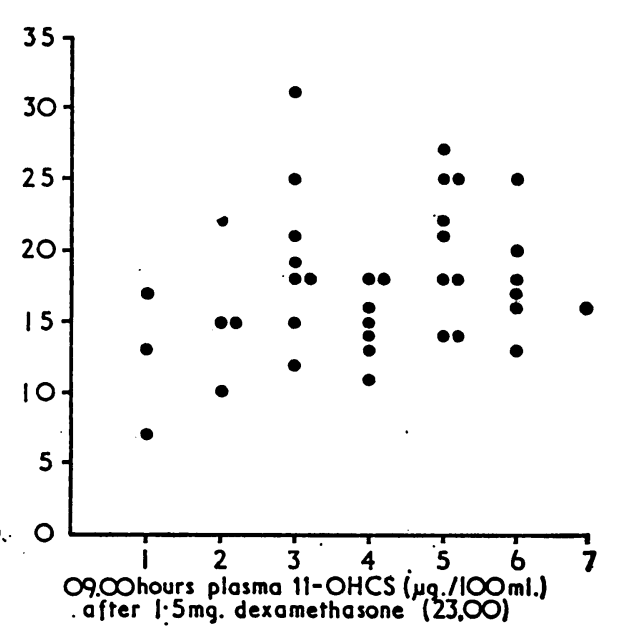

Fro. 3

FIG. 1.- 09.00 hours plasma 11-OHCS levels in normal subiects after varying doses of dexamethasone at 23.00 hours the previous night Fig. 2. - 09.00 hours plasma 11 -OHCS levels in normal subiects with differing doses of deramechasone in the same subjects. FIG. 3. - Baseline 24.00 hours plasma 11-OHCS levels in normal subjects plotted against suppression obtained after deramethasone (1.5 mg.). 
The plasma 11-OHCS levels after the dexamethasone dose are shown in Fig. 1. After $0.5 \mathrm{mg}$. of dexamethasone little suppression in plasma 11-OHCS level was obtained. After 1, 1.5, and $2 \mathrm{mg}$. of dexamethasone, plasma 11-OHCS levels were all $7 \mu \mathrm{g} . / 100 \mathrm{ml}$. or lower. In 14 normal subjects the suppression effect of three different doses of dexamethasone given at 23.00 hours as a single dose was studied. With the $0.5-\mathrm{mg}$. dose 11-OHCS levels did not fall below $6 \mu \mathrm{g} . / 100 \mathrm{ml}$. After doses of $1,1.5$, and $2 \mathrm{mg}$. plasma $11-\mathrm{OHCS}$ levels of $6 \mu \mathrm{g} . / 100 \mathrm{ml}$. or less were obtained but no clear dose response curve was observed.

Effect of Timing of Dose.-In eight normal subjects a comparison was made of the effect of dexamethasone in doses of $0.5 \mathrm{mg}$. at 23.00 hours, $0.5 \mathrm{mg}$. at 23.00 and 08.00 hours, and $1 \mathrm{mg}$. at 23.00 hours. In seven subjects who took $0.5 \mathrm{mg}$. at 23.00 and 08.00 hours the 09.00 hours plasma 11-OHCS levels were only slightly less than in the seven subjects who took a single dose of $0.5 \mathrm{mg}$. at 23.00 hours (Fig. 2). In four of the subjects a $1-\mathrm{mg}$. dose of dexamethasone at 23.00 hours produced suppression of plasma 11-OHCS to a lower level than $1 \mathrm{mg}$. in a divided dose.

Effect of Control 11-OHCS Level.-An attempt was made to correlate the control 09.00 hours plasma 11-OHCS levels with the levels obtained after $1.5 \mathrm{mg}$. of dexamethasone in the subjects studied. The results are shown in Fig. 3. The correlation coefficient ( $r$ ) between $x$, plasma 11-OHCS level after dexamethasone, and y, control 09.00 hours, 11-OHCS levels, is 0.25 . There is no association between $x$ and $y$, the regression not being significant ; $t=1.717, \mathrm{P}>0.05$.

\section{Hospital Inpatients}

As we wished to ensure maximal suppression with the minimum single dose, and initial results on control subjects, not subsequently confirmed, had suggested that the $1.5-\mathrm{mg}$. dose was more effective than the $1-\mathrm{mg}$. dose, the $1.5-\mathrm{mg}$. dose of dexamethasone was selected for study on hospital patients. At this dose we considered a normal response to be a 09.00 hours plasma 11-OHCS of $7 \mu \mathrm{g} . / 100 \mathrm{ml}$. or less after the 23.00 hours dose of dexamethasone.

Seventy-one patients were studied ( 39 males and 32 females). The control 09.00 hours plasma 11-OHCS levels did not differ significantly from the normal subjects with a range of 6-34 $\mu \mathrm{g} . / 100 \mathrm{ml}$.

The plasma 11-OHCS levels in the patients after the single 1.5-mg. dose of dexamethasone were markedly different from those in normal subjects. The results for patients are shown in Fig. 4. In 12 of the 39 male and in 14 of the 32 female patients the plasma $11-\mathrm{OHCS}$ levels were $8 \mu \mathrm{g} . / 100 \mathrm{ml}$. or more after dexamethasone. The plasma 11-OHCS level after dexamethasone was not dependent on either the baseline 11OHCS level or the age of the patient (Fig. 5). Some of the patients were questioned with regard to their sleep patterns. Five out of nine patients who had a " poor night's sleep" failed to suppress, compared with failure to suppress in 6 out of 23 who said that they had a " good night's sleep."

As the single 1.5-mg. dexamethasone dose failed to produce a normal response in a substantial proportion (36\%) of the inpatients tested, a further 38 patients were studied using a 2-mg. dose. The proportion of patients whose 11-OHCS level was suppressed to $7 \mu \mathrm{g} . / 100 \mathrm{ml}$. or below on this dose was little greater than on the $1.5 \mathrm{mg}$. dose (see Table).

\section{Outpatients}

In view of the difference in the findings between patients in hospital and normal subjects, studies were repeated, after discharge from hospital, on nine patients who had failed to sup- press as inpatients. In all but one the plasma 11-OHCS levels showed a normal response to $1.5 \mathrm{mg}$. of dexamethasone. In the one exception the result as an outpatient was $9 \mu \mathrm{g} . / 100 \mathrm{ml}$., compared with a plasma 11-OHCS of $12 \mu \mathrm{g} . / 100 \mathrm{ml}$. after dexamethasone as an inpatient. Repeat outpatient studies were also carried out on 15 of the patients who had shown normal suppression while inpatients. Thirteen showed a normal response. Of the other two, one had a plasma 11-OHCS value of $11 \mu \mathrm{g} . / 100 \mathrm{ml}$., compared with $6 \mu \mathrm{g} . / 100 \mathrm{ml}$, while an inpatient and the other had values of 14,15 , and $24 \mu \mathrm{g} . / 100 \mathrm{ml}$. on repeated tests, compared with $3 \mu \mathrm{g} . / 100 \mathrm{ml}$. as an inpatient. The latter patient was a 72-year-old woman with angina and peripheral vascular disease. Both this patient and the other are sure that the dexamethasone tablets were taken at the prescribed time.
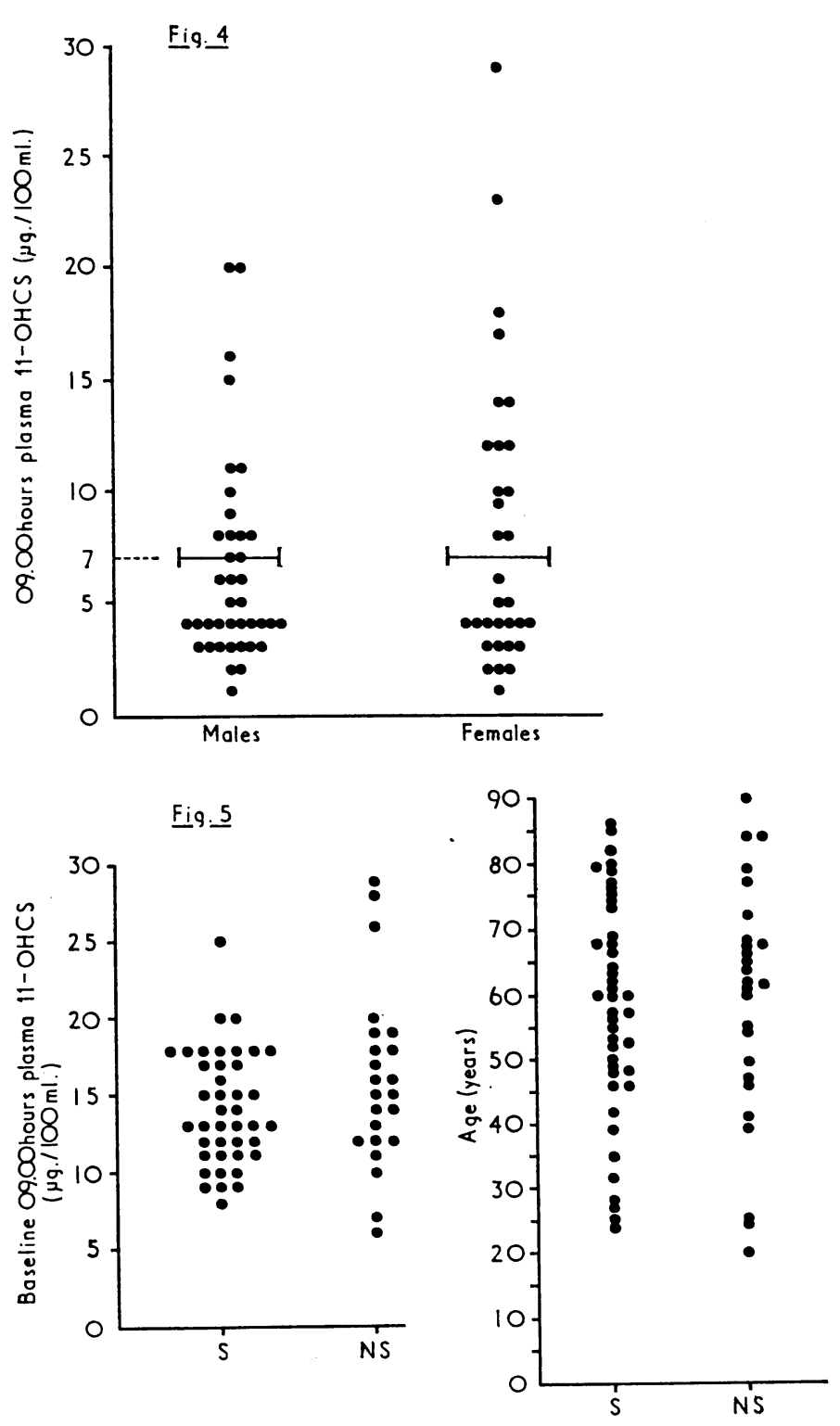

FIG. 4--09.00 hours plasma 11-OHCS levels after dexamethasone in hospital patients. FIG. 5.-Baseline 09.00 hours plasma cortisol levels and age distribution of hospital patients who did (S) or did not (NS)

Comparison of Plasma 11-OHCS Levels at 09.00 Hours of Inpatients After 1.5 and $2 \mathrm{mg}$. of Dexamethasone at 23.00 Hours

\begin{tabular}{ll|c|c}
\hline & $1.5 \mathrm{mg} .(71$ Subjects) & $2 \mathrm{mg}$. (38 Subjects) \\
\hline $11-\mathrm{OHCS} \geqslant 11 \mu \mathrm{g} . / 100 \mathrm{ml}$. &.. & $15(21 \%)$ & $6(16 \%)$ \\
$11-\mathrm{OHCS} 8-10 \mu \mathrm{g} . / 100 \mathrm{ml}$. &.. & $11(15 \%)$ & $6(16 \%)$ \\
$11-\mathrm{OHCS} \leqslant 7 \mu \mathrm{g} . / 100 \mathrm{ml}$. &.. & $45(63 \%)$ & $26(6 / 3 \%)$ \\
\hline
\end{tabular}




\section{Discussion}

The failure to demonstrate complete suppression of plasma 11-OHCS even after a 2-mg. dose of dexamethasone, or a dose response curve when plasma $11-\mathrm{OHCS}$ levels were $6 \mu \mathrm{g} . / 100 \mathrm{ml}$. or less, is most likely due to the limitations of the simple fluorimetric method for measuring plasma cortisol. Mattingly (1962) found what he considered to be "non-specific plasma fluorescence " equivalent to $0-4.2 \mu \mathrm{g} . / 100 \mathrm{ml}$. (mean $2.5 \mu \mathrm{g}$.) in patients after pituitary ablation and 0-7.8 $\mu \mathrm{g} . / 100 \mathrm{ml}$. (mean $2.6 \mu \mathrm{g}$.$) in patients on oral synthetic corticosteroids. James$ et al. (1967) have confirmed that a variable proportion of the total fluorescence is due to material other than cortisol.

It seems unlikely, however, that the assay procedure accounts for the difference which we have observed between the degree of suppression obtained after $1.5 \mathrm{mg}$. of dexamethasone in normal subjects and hospital inpatients. The failure to obtain suppression below $7 \mu \mathrm{g} . / 100 \mathrm{ml}$. in one-third of the inpatients may be due to the "stress" of being in hospital. We have observed in more than 100 patients (Connolly and Wills, unpublished data), including some of those patients in this study, that normal circadian variations are maintained despite hospital admission. It would therefore seem that the inability to obtain suppression after $1.5 \mathrm{mg}$. of dexamethasone is a more sensitive index of the "non-specific stress" of hospitalization than a disturbance in circadian rhythm.

The results we obtained with patients in hospital with the single-dose dexamethasone test, using either 1.5 or $2 \mathrm{mg}$., put in doubt the value of this method as a test for abnormal pituitary-adrenal function in hospital inpatients. The test would seem to be of value only as a rapid screening procedure to exclude those patients with a normal response.

\section{Summary}

A single-dose dexamethasone suppression test was studied in hospital staff and patients. The dexamethasone was given orally at 23.00 hours. Hospital staff showed a consistent suppression of plasma 11-OHCS levels at 09.00 hours to $7 \mu \mathrm{g} . / 100 \mathrm{ml}$. or less provided that the dose was at least $1 \mathrm{mg}$. Hospital inpatients did not show a consistent response, approximately one-third failing to show a suppression to $7 \mu \mathrm{g} . / 100 \mathrm{ml}$. after a single dose of either 1.5 or $2 \mathrm{mg}$. A higher proportion of outpatients showed a normal suppression response. It is concluded that as a test of normal pituitary-adrenal function the procedure is of value only for rapid screening, particularly applicable to outpatients.

We wish to thank Professor S. Sherlock, Dr. I. A. D. Bouchier, Dr. Nigel Compston, Dr. Cecil Symons, Dr. A. G. Beckett, Mr. L. R. H. Gracey, Mr. John Hopewell, and Mr. E. J. Radley Smith for permission to study patients under their care.

\section{REFERENCES}

Connolly, C. K., and Wills, M. R. (1967). Brit. med. f., 2, 25.

James, V. H. T., Townsend, J., and Fraser, R. (1967). F. Endocr., 37, Proceedings, p. XXVIII.

Kliman, B., and Peterson, R. E. (1960). F. biol. Chem., 235, 1639.

McHardy-Young, S., Harris, P. W. R., Lessof, M. H., and Lyne, C. (1967). Brit. med. f., 2, 740.

Mattingly, D. (1962). f. clin. Path., 15, 374.

Nichols, T., Nugent, C. A., and Tyler, F. H. (1965). f. clin. Endocr., 25, 343.

Nugent, C. A., Nichols, T., and Tyler, F. H. (1965). Arch. intern. Med., 116, 172 .

Pavlatos, F. C., Smilo, R. P., and Forsham, P. H. (1965). F. Amer. med. Ass., 193, 720 .

\section{Preliminary Communications}

\section{Sequential Analysis of Urinary Enzymes in Early Diagnosis of Parenchymal Damage after Renal Homotransplantation}

\section{Brit. med.F., 1968, 2, 667-669}

We have recently demonstrated experimentally (Meffan et al., 1968) that after unilateral nephrectomy complete transient ischaemia of the remaining kidney resulted in the early development of areas of focal acute tubular necrosis together with marked hyperplasia in the proximal convoluted tubules at the corticomedullary region. Associated with these histopathological changes were marked alterations in the levels of acid phosphatase, alkaline phosphatase, adenosine triphosphatase, and $\beta$-glucuronidase in the cortex, medulla, and papilla. These enzyme changes were in part due to attempted compensation in a remaining kidney recovering from ischaemia and in part to necrosis of tubular cells and desquamation of cells into the lumen of the tubules.

Two major causes of progressive tubular dysfunction after homotransplantation of the kidney are vascular thrombosis and immunological rejection. With the latter, ischaemia appears to be one of the first and most important events (Starzl, 1964). In both these conditions, therefore, as has been demonstrated
(Darmady et al., 1964), some necrosis and desquamation of cells will occur. In view of our findings with experimental renal ischaemia it would be expected that in such cases certain enzymes characteristic of renal tubular cells could occur in the urine at a concentration higher than normal. Furthermore, such increases should be detectable with the onset of the pathological process, before any clinical signs or symptoms of dysfunction of the transplanted kidney. It was therefore decided to undertake daily analyses of certain enzymes in the urine of a patient who received a cadaveric renal homotransplant, and who subsequently became anuric.

\section{Case Report and Results}

The patient was a 28-year-old man. Three years previously, during routine investigation before meniscectomy, he was found to be hypertensive (blood pressure $180 / 105 \mathrm{~mm}$. Hg), with albuminuria but no retinopathy. A provisional diagnosis of chronic nephritis was made on the basis of the history, intravenous pyelogram, and urinalysis; the blood urea at this time was $30 \mathrm{mg} . / 100$ $\mathrm{ml}$. Four months before transplantation he presented with a threemonth history of nausea, vomiting, weight loss, and blurring of vision; at that time his blood pressure was $240 / 160 \mathrm{~mm}$. $\mathrm{Hg}$ with associated grade 4 hypertensive retinopathy. The blood urea was associated grade 4 hypertensive retinopathy. The blood urea was $116 \mathrm{mg} . / 100 \mathrm{ml}$. and he had gross albuminuria. $\mathrm{He}$ became progressively uraemic, and ultimately required peritoneal dialyses. 